\title{
Artificial Intelligence in Strategic Foresight - Current Practices and Future Application Potentials
}

\author{
Current Practices and Future Application Potentials
}

\author{
Patrick, P., Brandtner \\ University of Applied Sciences Upper Austria \\ patrick.brandtner@fh-steyr.at
}

\begin{abstract}
The amount of data and information is growing rapidly and exponentially. A similar degree of change applies to market dynamics, volatile customer requirements, shortened product lifecycles and the amounts of environmental uncertainties in the context of organisational innovation management. Strategic Foresight (SF) offers an approach to deal with environmental uncertainty and Artificial Intelligence (AI) has huge potential to support SF by means of collecting and analysing data as well as automatizing information research and analysis tasks. The current paper analyses the potentials and organisational practices at the nexus of $\mathrm{AI}$ and $\mathrm{SF}$. In the form of expert interviews, current practices and expected future application potentials of $\mathrm{AI}$ in SF are analysed. Furthermore, challenges and potential weaknesses of $\mathrm{AI}$ in this context are discussed and an outlook on potential future visions of AI in SF from practitioners' points of view is provided. The results show that currently AI is only applied in a very limited way to support SF, mostly in terms of supporting trend and customer data analysis. However, the results also indicate high future potentials of $\mathrm{AI}$ in SF. Experts agree that AI will have a high impact on SF, mainly in terms of automatizing information research and data analysis tasks and subsequently allowing employees to focus on more complex tasks in SF which require human abilities like intuition, creativity, courage and entrepreneurial thinking.t.
\end{abstract}

\section{CCS CONCEPTS}

- Applied computing $\rightarrow$ Enterprise computing; • Information systems $\rightarrow$ Information systems applications; • Computing methodologies $\rightarrow$ Artificial intelligence.

\section{KEYWORDS}

Strategic Foresight, Artificial Intelligence, Innovation Management, Digitalization, Corporate Foresight, Data Analytics

ACM Reference Format:

Patrick, P., Brandtner and Marius, M. A., Mates. 2021. Artificial Intelligence in Strategic Foresight - Current Practices and Future Application Potentials: Current Practices and Future Application Potentials. In The 2021 12th International Conference on E-business, Management and Economics (ICEME 2021), July 17-19, 2021, Beijing, China. ACM, New York, NY, USA, 7 pages. https://doi.org/10.1145/3481127.3481177

Publication rights licensed to ACM. ACM acknowledges that this contribution was authored or co-authored by an employee, contractor or affiliate of a national government. As such, the Government retains a nonexclusive, royalty-free right to publish or reproduce this article, or to allow others to do so, for Government purposes only. ICEME 2021, fuly 17-19, 2021, Beijing, China

(C) 2021 Copyright held by the owner/author(s). Publication rights licensed to ACM ACM ISBN 978-1-4503-9006-4/21/07 ..\$15.00

https://doi.org/10.1145/3481127.3481177

\author{
Marius, M. A., Mates \\ University of Applied Sciences Upper Austria \\ Marius-Adrian.Mates@students.fh-steyr.at
}

\section{INTRODUCTION}

The amount and relevance of data being produced in virtually every field has been growing significantly over the last decades. The importance of data as decision base is not only recognized in organizational practice, but is also a topic of high interest in academia. A growing number of papers is related towards the application and utilization of data in a variety of settings. Besides the data itself, methods and techniques for analysing it are considered as critical capabilities in the era of digitalization [1]. One of the research domains including a broad range of methods for analysing data is Artificial Intelligence (AI). An acknowledged definition of AI goes back to [2], defining it as "a system's ability to correctly interpret external data, to learn from such data, and to use those learnings to achieve specific goals and tasks through flexible adaptation" [2, p. 15). Furthermore, AI refers to a variety of analytical methods, which can be applied to executive certain task formerly done by humans respectively human intelligence. The goal of AI is to create systems that mimic human functions based on their experience and without the necessity of manual intervention [3]. Although nothing new, there are several developments that have led to an increasing relevance and presence of $\mathrm{AI}$ in virtually every organisational domain: First, the rise of the data amounts generated in every business process and in the course of our every-day-lives provides a huge source of raw-material in the form of data for AI applications. Second, the rise of cloud-computing and cloud-storage further facilitates the sharing and analysis of data. Third, the ongoing process of digitalization alongside with increasing hardware performance and the implementation of sensor on a broad array of devices and setting leads to evolvement of cyber-physical system, which again continuously produce data which fuels AI application [4].

One of the domains heavily impacted by Artificial Intelligence is innovation management and in this context especially the area of Strategic Foresight (SF) [5]. SF can be defined as a "dual purpose task of 1) observing, perceiving, and capturing factors that is likely to induce future changes, and 2) dealing with these changes by deciding appropriate organizational responses." [6, p. 87]. The potential of applying automated, AI-based data analysis in SF has already been identified in pertinent literature $[7 ; 8 ; 9]$. Although academia and practitioners agree that Strategic Foresight is highly relevant for the long-term success of organizations, the dominant SF practice still seems to be that it is done in a traditional way by means of manually collecting and analysing data and information [10]. The need for identifying and analysing organizations that already apply AI in SF is high and it is stated, that all commercial organizations should start adopting AI and the usage of data for supporting and facilitating Strategic Foresight, trend analysis, 
and executive decision-making [11]. The current paper focusses on exactly this research gap and addresses the following research question: How is Artificial Intelligence applied in Strategic Foresight in organizational practice?

For separation of concerns and in regard to the identified research gap, the following sub-questions are defined:

- What are the already implemented applications of AI in SF practice? (result: current Strategic Foresight activities and processes where AI is already used in practice, cf. section AAA)

- What are possible, future application fields of AI for SF in the respective organisation? (result: potential future application fields as seen in the specific organization's foresight practice, cf. section BBB).

- What are the main challenges that hinder the application of AI in organizational foresight and which prerequisites have to be given for its successful implementation? (result: main barriers for $\mathrm{AI}$ in practice and critical prerequisites seen by practitioners, cf. section CCC).

- What is the practitioners' perception of the general development of $\mathrm{AI}$ in $\mathrm{SF}$ in the next five years from now? (result: general future relevance of $\mathrm{AI}$ in Strategic Foresight as perceived by practice).

The rest of the paper is structured as follows: section two provides a detailed description of the research methodology applied (i.e. expert interviews). Section three presents the main results of the paper in the form of (i) current AI applications and their benefits in SF, (ii) future application fields of $\mathrm{AI}$ in $\mathrm{SF}$ as planned in the respective organization, (iii) the main challenges and the most important prerequisites for applying $\mathrm{AI}$ in $\mathrm{SF}$ and (iv) the general perception of the future of $\mathrm{AI}$ in $\mathrm{SF}$ as stated by practitioners on the level of the single cases. Finally, section four concludes the paper and provides a summary and discussion of overall results as well as the conclusion of the paper including its limitations and future work.

\section{RESEARCH METHDOLOGY OF THE PAPER}

This section provides a summary of the research method applied in carrying out this study. As the aim of the paper is to analyze the perception and usage of AI in SF practice, we selected expert interviews as an appropriate method for data collection. Expert interviews are qualitative, either semi-structured or open, interviews with an expert (i.e. a person holding expert knowledge) [12] Expert interviews are particularly useful when the purpose of data collection is gaining insights into a specific application context (i.e. AI in SF). Additionally, expert interviews are well suited for identifying implicit domain knowledge, which would be impossible or hard to collect by means of quantitative methods as a survey [13] When conducting expert interviews, three basic elements have to be considered: 1) expert identification and selection, 2) data collection procedure and 3) data analysis approach. In the following sections 2.1, 2.2 and 2.3 these elements and their specific details in the course of the current paper are explained.

\subsection{Expert Identification and Selection}

In literature, there are two possible ways of how to identify and select experts for an expert interview: a) random selection and b) information oriented selection. Random sampling (a) is especially useful when the goal of the research to generate results, that allow for generalization of findings for a larger population. Information oriented sampling (b) on the other hand is particularly useful for the goal of obtaining knowledge from small but precisely targeted samples and for specific, focused domains and research areas [14]. In regards to the defined goal of the paper, an information oriented sampling was applied in order to ensure the selection of actual SF experts with a background of AI. This approach allows for generating results from a smaller sample size and still assures the expert role of the identified interview participants.

More precisely, we applied an expert-search using the current research network of our university as wall as the social media platforms LinkedIn (https://www.linkedin.com) and Xing (https: //www.xing.com) to identify potential experts based on their job description, their educational background and their working history. In a first step, 34 potential interview participants where contacted, of which 18 agreed to a first call to clarify their expert role. After these initial calls, 14 people were found to fulfil the required background of both SF and AI. Out of this 14 experts, 11 actually took part in the conducted interviews. The following table provides an overview of the selected experts, their background and their position in the organisation (as requested by all participants, their names of as well as the names of their organisations had to be anonymized):

The composition of selected experts shows a broad variety of industries and backgrounds. In total, 11 experts from 11 different organisations agreed to participate in the interviews. The background of the participants ranges from C-level to senior- and general management-level positions. Each of the experts has a solid background knowledge in the application of Strategic Foresight and AI knowhow and at least six years of relevant working experience in this context.

\subsection{Procedure of Data Collection}

The data collection procedure builds on the four instruments of expert interviews: (i) short introductionary questionnaire, (ii) semistructured interview guideline, (iii) audio recordings of the interviews and (iv) generation of transcripts of recordings as basis for result analysis [15].

In the beginning of each interview, a short introduction questionnaire (i) was used to collect general information to confirm the actual expert level of the person (i.e. working and educational background, organisation and working history) Secondly, an interview guideline (ii) was developed and applied to gather the answers to the defined research questions. In total, the questionnaire consisted of four main question areas and several sub-question. The main question areas included (i) what are current AI applications in SF, (ii) what are planned future AI applications in SF, (iii) which prerequisites have to be given and which challenges occur in the context of applying AI in SF and (iv) what is the general future vision of $\mathrm{AI}$ in SF in the next five years. The sub-questions were defined for each of the four areas in case the interviews would slow down 
Table 1: Participants of the Expert Interviews

\begin{tabular}{lll}
\hline Participant number & Industry & Position in organization \\
1 & Agricultural machinery & Innovation \& technology manager \\
2 & Software & Expert for AI in innovation management \\
3 & Welding equipment & R\&D manager \\
4 & Food industry & Digitalization and innovation manager \\
5 & Packaging industry & Innovation coordinator \\
6 & Consultancy & Senior innovation consultant \\
7 & AI software & Technology advisor, Head of AI board \\
8 & Industrial machinery & Chief technology \& digitalization officer \\
9 & Automation & Business innovation manager \\
10 & Construction machinery & Digital \& IT innovation manager \\
11 & Consultancy & Head of innovation and Business Dev. \\
\hline
\end{tabular}

or no answers or too short answers were given. The advantage of applying such a semi-structured interview guideline is that it serves as an orientation framework for both the interviewer and the interviewee. Hence, it provides a higher degree of comparability as compared to a narrative interview. The questions were furthermore not used in a strict sequence, but were rather applied as a navigation help following the flow of the interview in order to ensure that all important points were discussed [16]. Following and supported by the interview guideline, the interviewer took notes of the most important answers and results. As mentioned all of the interviews were also recorded (iii) and these recordings served as the basis for the subsequent transcription of the interviews (iv). In combination with the notes taken by the interviewer, these transcripts ensured detailed and complete data collection [17].

\subsection{Data Analysis Approach}

The initial step of data analysis was to structure the collected data of the notes and interview transcriptions. For each interview, a single case analysis was generated. More precisely, the results per each interview were generated in a first step and the overall results were produced by comparing and matching these single cases. By this means, an in-depth analysis of the single cases as well as a comparison of overall results and the identification of differences between the eleven experts was guaranteed [18].

Each of the eleven cases was analysed in regards to the same dimensions which are as follows:

- Description of the organization's background

- Current AI applications in SF

- Planned AI application in SF

- Future picture of AI in SF in five years from now

- Main challenges / prerequisites of $\mathrm{AI}$ in SF

The results of the single cases are provided in section 3 , followed by the discussion of overall results in section 4 of the paper.

\section{RESULTS OF SINGLE CASES OF EXPERT INVERVIEWS}

The results of each interview case are presented in the following table, which provides the details on the level of each company respectively the respective expert (ID 1-11):

\section{OVERALL RESULT DISCUSSION AND CONCLUSION}

Based on the single case results presented in section 3, the overall results of the expert interviews are discussed and summarized on the cross-case level, in section 4. In 4.1., current applications of $\mathrm{AI}$ in $\mathrm{SF}$ and in general in the organizations are summarized in a first step (4.1.1). Second, potential future and or currently planned applications of $\mathrm{AI}$ in SF (4.1.2) in practice as well as the main challenges and prerequisites of $\mathrm{AI}$ in SF (4.1.3) are discussed. In 4.1.4., the general vision respectively opinion of future application of $\mathrm{AI}$ in SF from the experts' point of view is presented. Finally, 4.2. concludes the paper, reflects on limitations and provides an outlook on future research issues in the context of $\mathrm{AI}$ and SF.

\subsection{Discussion of Overall Results}

4.1.1 Current Applications of AI in SF and in the Organisation. The current applications of $\mathrm{AI}$ in Strategic Foresight are mainly focused on trend monitoring and strategic issue identification processes. Although most of the experts state that there is basically a high potential of AI in SF, most of the organisations are not using AI in SF in a systematic and broader way. Regarding the general application of AI across organisational domains, AI is seen as a supporting technology and is already applied in a couple of areas, including e.g. image recognition, customer demand and order prediction or general strategic planning activities.

In summary, the main current applications of AI either in SF or in the general organisational backgrounds include:

- Five out of 11 experts state that their organisations are already applying AI, 2 out of them in Strategic Foresight, three out of them in other areas and departments

- The tow current application of AI in SF focus on i) trend management and strategic issue identification and ii) product and service improvement potential detection

- The three current applications of AI outside SF focus on i) customer and order demand prediction, ii) image recognition and iii) general strategic planning support

4.1.2 Potential Future or Planned Applications of AI in SF. Regarding future plans or future potentials of applying AI in SF, most of the organisations identify and state high potential. The main 
Table 2: Results of the Expert Interviews

\begin{tabular}{|c|c|c|c|c|c|}
\hline ID & $\begin{array}{l}\text { Description of } \\
\text { company }\end{array}$ & $\begin{array}{l}\text { Current AI } \\
\text { applications in SF }\end{array}$ & $\begin{array}{l}\text { Future planned } \mathrm{AI} \\
\text { Applications in SF }\end{array}$ & $\begin{array}{l}\text { Future picture of } \mathrm{AI} \text { in } \\
\mathrm{SF} \text { ( } 5 \text { years) }\end{array}$ & $\begin{array}{l}\text { Main Challenges / } \\
\text { Prerequisites of } \mathrm{AI} \text { in SF }\end{array}$ \\
\hline 1 & $\begin{array}{l}\text { Producer of } \\
\text { agricultural } \\
\text { machinery and } \\
\text { equipment for smart } \\
\text { farming, over } 1.800 \\
\text { employees }\end{array}$ & $\begin{array}{l}\text { No current } \\
\text { applications of } \mathrm{AI} \text { in } \\
\mathrm{SF} \text {, but for image } \\
\text { recognition in } \\
\text { regards to farming } \\
\text { grounds and fruit } \\
\text { ripeness }\end{array}$ & $\begin{array}{l}\text { Collaboration with a } \\
\text { start-up in the context of } \\
\text { AI-based trend } \\
\text { recognition is planned }\end{array}$ & $\begin{array}{l}\text { AI will prepare findings } \\
\text { and data in a way that } \\
\text { people can focus on the } \\
\text { creativity and } \\
\text { experience based aspects } \\
\text { of SF }\end{array}$ & $\begin{array}{l}\text { The main challenge is to } \\
\text { be able to handle the } \\
\text { increasing amounts of } \\
\text { data in the organisation }\end{array}$ \\
\hline 2 & $\begin{array}{l}\text { Provider and } \\
\text { developer of trend } \\
\text { management and } \\
\text { innovation software } \\
\text { for strategic planning, } \\
\text { over } 100 \text { employees }\end{array}$ & $\begin{array}{l}\text { AI is applied for } \\
\text { supporting } \\
\text { software-based } \\
\text { trend recognition in } \\
\text { some departments, } \\
\text { mainly Machine } \\
\text { Learning algorithms }\end{array}$ & $\begin{array}{l}\text { Plan is to apply AI in } \\
\text { trend recognition } \\
\text { throughout the } \\
\text { organisation, goal: more } \\
\text { time for other activities } \\
\text { for employees }\end{array}$ & $\begin{array}{l}\text { AI will do all those tasks, } \\
\text { that can be automatized } \\
\text { in SF, employees will } \\
\text { have more time for more } \\
\text { projects, AI enables and } \\
\text { supports learning }\end{array}$ & $\begin{array}{l}\text { Before even thinking } \\
\text { about AI ins SF, in most } \\
\text { companies a deeper and } \\
\text { better understanding of } \\
\text { SF has to be given }\end{array}$ \\
\hline 3 & $\begin{array}{l}\text { Producer of welding } \\
\text { technology, solar } \\
\text { power equipment and } \\
\text { battery storage, over } \\
5000 \text { employees }\end{array}$ & $\begin{array}{l}\text { No actual } \\
\text { application, } \\
\text { currently } \mathrm{AI} \text { is } \\
\text { analysed in terms of } \\
\text { its applicability to } \\
\text { identify new } \\
\text { product features }\end{array}$ & $\begin{array}{l}\text { AI projects that will } \\
\text { build on data from } \\
\text { connected devices, the } \\
\text { results will enable the } \\
\text { prediction of insights, e.g. } \\
\text { usage patterns for } \\
\text { product development }\end{array}$ & $\begin{array}{l}\text { AI will be able to } \\
\text { support many tasks, but } \\
\text { will always be limited } \\
\text { regarding intuition, risk, } \\
\text { bravery and } \\
\text { entrepreneurial } \\
\text { thinking. }\end{array}$ & $\begin{array}{l}\text { Missing competencies in } \\
\text { the area of data analytics } \\
\text { as well as the ability to } \\
\text { operationalize findings }\end{array}$ \\
\hline 4 & $\begin{array}{l}\text { Producer of food and } \\
\text { agricultural } \\
\text { marketing company, } \\
\text { over } 2600 \text { employees }\end{array}$ & $\begin{array}{l}\text { No current } \\
\text { applications of AI. }\end{array}$ & $\begin{array}{l}\text { Pilot projects are planned } \\
\text { in the area of production } \\
\text { and logistics. }\end{array}$ & $\begin{array}{l}\text { AI is limited in SF } \\
\text { because in always } \\
\text { focusses on learning } \\
\text { from past data. The past } \\
\text { is no indictor for } \\
\text { innovation. }\end{array}$ & $\begin{array}{l}\text { The quality of } \\
\text { information sources is } \\
\text { too low - safe, reliable } \\
\text { and secure data is } \\
\text { needed as a } \\
\text { prerequisites. }\end{array}$ \\
\hline 5 & $\begin{array}{l}\text { Producer of food- and } \\
\text { non-food packaging, } \\
\text { over } 5000 \text { employees }\end{array}$ & $\begin{array}{l}\text { No current } \\
\text { applications of } \mathrm{AI} \text { in } \\
\mathrm{SF} \text {, but } \mathrm{AI} \text { is applied } \\
\text { in demand and order } \\
\text { prediction. }\end{array}$ & $\begin{array}{l}\text { A project to combine and } \\
\text { analyse internal and } \\
\text { external information is } \\
\text { planned. AI can improve } \\
\text { and automate this. }\end{array}$ & $\begin{array}{l}\text { AI will be mostly useful } \\
\text { in automated trend } \\
\text { identification. This is a } \\
\text { task that is really time } \\
\text { consuming and blocks } \\
\text { employees. }\end{array}$ & $\begin{array}{l}\text { The ability to combine } \\
\text { internal data and } \\
\text { experience with the } \\
\text { right extern data sources } \\
\text { and derive tangible } \\
\text { findings for actions is } \\
\text { crucial }\end{array}$ \\
\hline 6 & $\begin{array}{l}\text { Single-person } \\
\text { consulting company } \\
\text { in the area of } \\
\text { innovation } \\
\text { management and } \\
\text { service dev. }\end{array}$ & $\begin{array}{l}\text { No current } \\
\text { applications of AI. }\end{array}$ & $\begin{array}{l}\text { No concrete future } \\
\text { initiatives are planned. }\end{array}$ & $\begin{array}{l}\text { AI has huge potential in } \\
\text { identifying trend } \\
\text { patterns, visualizing and } \\
\text { combining information } \\
\text { and showing blind spots }\end{array}$ & $\begin{array}{l}\text { The possibility that AI } \\
\text { could potentially } \\
\text { contradict human } \\
\text { experience or gut feeling } \\
\text { has to be accepted. }\end{array}$ \\
\hline 7 & $\begin{array}{l}\text { Software company } \\
\text { with a focus on } \\
\text { providing } \\
\text { development } \\
\text { environments for AI } \\
\text { applications, } \sim 10 \\
\text { employees }\end{array}$ & $\begin{array}{l}\text { AI is applied to } \\
\text { automate processes } \\
\text { and especially } \\
\text { decisions, mainly } \\
\text { neural networks and } \\
\text { machine learning is } \\
\text { applied }\end{array}$ & $\begin{array}{l}\text { Goal is to enable } \\
\text { hybrid-decision systems } \\
\text { which include the best of } \\
\text { AI an human intelligence }\end{array}$ & $\begin{array}{l}\text { AI will automate simple } \\
\text { and repetitive tasks, } \\
\text { employees can focus on } \\
\text { real value relevant } \\
\text { processes. }\end{array}$ & $\begin{array}{l}\text { A company-wide } \\
\text { database as well a } \\
\text { appropriate data has to } \\
\text { be given or at least a } \\
\text { clear data strategy has } \\
\text { to be defined }\end{array}$ \\
\hline 8 & $\begin{array}{l}\text { Producer of } \\
\text { machinery and } \\
\text { equipment for mobile } \\
\text { crushing and } \\
\text { screening equipment, } \\
\text { over } 6000 \text { employees }\end{array}$ & $\begin{array}{l}\text { AI is an ongoing } \\
\text { topic of interest in } \\
\text { the context of } \\
\text { product and service } \\
\text { development. No } \\
\text { real applications yet. }\end{array}$ & $\begin{array}{l}\text { No concrete plans as } \\
\text { business and use cases } \\
\text { are still missing. }\end{array}$ & $\begin{array}{l}\text { AI will succeed, but not } \\
\text { because of the } \\
\text { technology - only } \\
\text { because of use cases } \\
\text { which have to get more } \\
\text { tangible. }\end{array}$ & $\begin{array}{l}\text { The benefit is not } \\
\text { tangible yet - use cases } \\
\text { are needed to show it } \\
\text { and motivate } \\
\text { organisations to use AI. } \\
\text { Without use cases and } \\
\text { benefits there will be no } \\
\text { application. }\end{array}$ \\
\hline
\end{tabular}


Table 2: Continued

\begin{tabular}{|c|c|c|c|c|c|}
\hline 9 & $\begin{array}{l}\text { Producer and } \\
\text { developer of } \\
\text { automation solutions } \\
\text { for different } \\
\text { industries and service } \\
\text { sectors, over } 1700 \\
\text { employees }\end{array}$ & $\begin{array}{l}\text { AI is applied for } \\
\text { identifying current } \\
\text { issues and topics in } \\
\text { strategic planning, } \\
\text { separate Data } \\
\text { Scientists are } \\
\text { employed }\end{array}$ & $\begin{array}{l}\text { Application of } \mathrm{AI} \text { in the } \\
\text { context of patent } \\
\text { analysis to predict future } \\
\text { technological } \\
\text { developments. }\end{array}$ & $\begin{array}{l}\text { AI will be supporting } \\
\text { many rational areas, } \\
\text { however, in SF there are } \\
\text { also non-rational } \\
\text { decisions necessary and } \\
\text { AI will be limited in SF } \\
\text { in this regard. }\end{array}$ & $\begin{array}{l}\text { The storage of } \\
\text { know-how and } \\
\text { information in a } \\
\text { company-wide, shared } \\
\text { data-bases that can be } \\
\text { enriched with external } \\
\text { data. }\end{array}$ \\
\hline 10 & $\begin{array}{l}\text { Producer of compact } \\
\text { construction } \\
\text { machinery and } \\
\text { equipment, over } 6000 \\
\text { employees }\end{array}$ & $\begin{array}{l}\text { No current } \\
\text { applications of AI. }\end{array}$ & $\begin{array}{l}\text { No concrete plans of } \\
\text { applying AI in SF, it has } \\
\text { to get more intuitive and } \\
\text { understandable. }\end{array}$ & $\begin{array}{l}\text { AI will be important in } \\
\text { SF, it has huge potential } \\
\text { in trend and technology } \\
\text { scouting. }\end{array}$ & $\begin{array}{l}\text { Missing top } \\
\text { management } \\
\text { commitment and a lack } \\
\text { of resources and } \\
\text { know-how are the } \\
\text { biggest barriers. }\end{array}$ \\
\hline 11 & $\begin{array}{l}\text { Consulting company } \\
\text { for strategic } \\
\text { innovation projects, } \\
15 \text { employees }\end{array}$ & $\begin{array}{l}\text { No current } \\
\text { applications of AI. }\end{array}$ & $\begin{array}{l}\text { No concrete applications } \\
\text { of AI in SF. }\end{array}$ & $\begin{array}{l}\text { AI will definitely play an } \\
\text { important role in some } \\
\text { parts, but it is difficult to } \\
\text { grasp and understand } \\
\text { from the SF perspective. }\end{array}$ & $\begin{array}{l}\text { The biggest hinderer is } \\
\text { that AI will never be } \\
\text { able to replace human } \\
\text { gut feeling. That point is } \\
\text { often used as an excuse } \\
\text { for not dealing with AI } \\
\text { in SF yet. }\end{array}$ \\
\hline
\end{tabular}

benefits offered by AI on the context of SF is seen as providing decision support for trend evaluation, automatizing certain repetitive activities like trend monitoring and creating a shared information and knowledge base including internal and external information as well as the generation of findings out of it.

In summary, the main future potentials that are seen for AI in SF respectively the already planned future activities of applying it in SF include the following points:

- Identification of new knowledge and trends by being able to analyzing larger sets and amounts of data in a automated way.

- Collection and deduction of customer and usage patterns as a basis for deciding on new product or service features.

- In general, most organization see a huge potential that AI could fulfil repetitive, time-intensive tasks like scanning databases or content sources and could subsequently provide employees with more time for creative and gut-feeling respectively experience-based activities.

- Efficient usage of resources by focussing in essential areas. AI could automatically identify the core meanings and results out of huge data amounts, the organisations can then better focus on what really matters.

- Creation of transparency, objectivity and quality by building decisions not only on gut feeling or potentially biased experiences but also on reliable, objective data and information

In terms of long-term plans and initiatives in the context of AI in SF, the following scenarios were described by the experts:

- Expert 1 stated that there is currently an initiative planned for using AI to conduct the data collection and analysis in trend management and by that provide employees with more time for creative tasks and the combination and interpretation of results and data.
- Expert 2 mentioned that there are ideas about implementing an "army of AI-bots" in SF, where each focusses on specific topics and areas and collects the latest information continuously and automatically. According to this expert, such a system could shorten innovation cycles and is able to provide up to $60 \%$ more information in a certain topic than humans ever could. Hence, AI will proactively show recommendations for defined topics and concrete investment alternatives.

- Expert 4 explained that there are currently initiatives in production and logistics. The goal of these initiatives to provide relevant information to the right employee at the right time based on AI. The benefits of ensuring a perfect information availability are also potentially seen in SF, where humans could then focus on strategic tasks much more.

4.1.3 Main Challenges and Prerequisites of $A I$ in SF. As most of the experts stated that they are not applying $\mathrm{AI}$ in the organization yet, there are several challenges that hinder respectively many prerequisites that have to be given in the context of applying AI in SF and in general. The expert agree that AI has huge potential, however, they also state that without tangible and easy to understand use cases and proven benefits, it will take quite some time till AI application increases in practice.

Furthermore, a big group of challenges is identified in the context of having and working with large amounts of data, that represent the basis for AI applications.

The following list provides a summary of the biggest challenges and most important prerequisites for AI:

- The competencies and capabilities required to handle large amounts of data are a key prerequisite for applying AI not only in SF but in the organisation in general

- Before thinking about applying AI, a certain level of SF maturity in terms of a strategically oriented and forward thinking 
organisation which takes the corporate environment into consideration has to be given

- The availability of valid, trustable and secure data from serious and trustable sources is key for reliable AI findings in SF

- The organisation definitely needs to have common data acquisition and usage strategy. This strategy should not only provide the approach to and sources of data but also the ways of how to handle, analyse and integrate data into the decision making process in SF.

- A missing top management support and alongside with that too little resources available for AI applications in SF and $\mathrm{SF}$ in general seem to be the biggest hinderers. A reason for this is also stated in the fact, that it is hard to directly see the impact and importance of SF on the one hand and also to understand the potential of $\mathrm{AI}$ in this context on the other hand.

- A big challenge or perceived danger is the risk that AI could lead to results that contradict existing ideas and projects and are hard to accept by management and employees.

4.1.4 Future Picture of AI in SF in the Next Five Years. Regarding the general perception of the future of $\mathrm{AI}$ in $\mathrm{SF}$, there are positive as well as negative statements from the group of experts. In total, 6 out of 11 experts focus on the overall positive impact of AI on SF, 1 expert has a neutral perspective and 4 experts rather seem to expect negative impacts of $\mathrm{AI}$ in SF.

Summarizing the positive, long-term pictures of $\mathrm{AI}$ in $\mathrm{SF}$, the experts stated the following:

- Expert 2 stated that AI will influence the complete innovation process at the Front End of Innovation as well as in terms of innovation decisions, innovation portfolio development and innovation roadmap definition in the future.

- Although perceived as being limited in terms of the focus on past data, participant 4 indicated that AI will allow for a much broader understanding of customers based on an extensive analysis of customer data.

- Interview partner 5 anticipates that AI will replace manual, repetitive activities like information research and collection related tasks. AI is expected to be able to conduct it in a more efficient and resource friendly way.

- Expert 6 identified the main future application potentials of $\mathrm{AI}$ in SF in terms of supporting i) pattern recognition (e.g. trend evolvement patterns, technology rise patterns etc.), ii) visualization of trends and events, iii) data analytics of broader arrays of information (patent data, web data, internal data, external data, structured and unstructured data etc.) and showing blind spots (i.e. where knowledge and information is missing and has to be built up or integrated into the organizational processes). Expert 9 agrees with this point of view.

- Similar to participant 5, also participant 7 stated that AI will overtake simple and repetitive tasks in SF in the future, enabling human employees to focus on more complex, creativity and intuition driven tasks.

Summarizing the negative, long-term pictures of $\mathrm{AI}$ in SF, the experts stated the following:
- Expert 1 expects the effort required for implementing $\mathrm{AI}$ in $\mathrm{SF}$ as unpredictable and rather high. Hence, it will be really difficult to justify initiatives in this context.

- Participant 3 sees the main limitations of AI in SF in the fact that it may not and never be able to include important entrepreneurial abilities like courage, risk and intuition.

- Interviewee 4 mentioned that AI's focus on past data is the main limitations, because future innovation potentials are not always reflected or identifiable in past data.

- Expert 9 simply concluded that there is more to SF than AI (at least as we imagine it now).

- Participant 2 concluded that the main difficulty of $\mathrm{AI}$ is that it will always remain at a supportive level and that human abilities are much more important in SF. The participant also stated that AI will never be able to decide which investments to take or which specific solutions a customer needs.

- Expert 3 identifies on big issue with AI in terms of that it is well suited to collect and condense data and information in SF, however, it may not be able to critically discuss and interpret the contextualized implications of the data on the specific organisation (this will remain a human task).

\subsection{Conclusion and Limitations}

The current paper analyzed the current applications and expected future application potentials as well as main challenges and limitations of AI in SF. The main research question was to identify, how AI is applied in SF based on expert opinions in organizational practice. For separation of concern, four sub questions were derived, addressing the following aspects: i) current application fields (cf. section 4.1), ii) future planned and / or possible applications within the respective organisations (cf. section 4.2), iii) main challenges (cf. section 4.3) and iv) general future perception of AI in SF (cf. section 4.4). The detailed results were presented in section 3 based on the single company level and were discussed across companies in section 4.1 of the paper.

In conclusion, it can be found that $\mathrm{AI}$ is currently only applied in a limited way in the context of SF. Most current application fields are focused on i) trend recognition and data analysis of internal and external data sets and ii) identifying product and service improvement potentials based on e.g. customer input or general market data. Hence, trend recognition and evaluation respectively data analysis for reducing uncertainty of trends and customer requirement developments are the dominant current application fields. Although only a few of the analysed companies already apply AI, most of the experts agree that AI offers high potential in this context. Main benefits are found to be in the form of automatizing manual tasks, providing better overview of huge data and information sets and offering more objective approaches to data and information analysis. Regarding currently planned initiatives, the main focus is again on trend monitoring and strategic uncertainty reduction by means of AI based data collection, analysis and trend identification.

The main challenges of $\mathrm{AI}$ in SF and also the main reasons why AI has not yet been applied in this context can be summarized as i) difficult to identify the required effort to implement AI, ii) hard to show the direct benefit and quantitative improvements brought by $\mathrm{AI}$ in SF, iii) missing abilities and competencies in terms of data 
analytics and data science, iv) missing data usage strategies and legal constraints and v) the fear of unwanted impacts on current innovation projects and organizational targets.

Future application fields are seen as high and mainly lie in the context of providing decision support and enabling employees to focus on human abilities like intuition, creativity, social capabilities, entrepreneurial thinking and courage respectively risk taking. These human abilities were also mentioned to be the main limitations why AI may always only remain a supportive approach in SF, but may never (at least based on the experts current understanding of $\mathrm{AI}$ ) replace human beings.

The main limitation of the paper is the limited amount of experts included in the expert interviews. Furthermore, all of the expert were either based in Austria or Germany. However, by applying the careful and systematic expert selection procedure, we ensured that real experts were approached and selected, hence, it is ensured that results are based on real expertise. Building on the current paper, future research could focus on extending the focus of the paper to more experts from additional industries and areas as well as from different countries. Also, the applied expert interview procedure may be applicable for different research settings as well.

\section{ACKNOWLEDGMENTS}

This research was financed by research subsidies granted by the government of Upper Austria.

\section{REFERENCES}

[1] T. Papadopoulos, S. P. Singh, K. Spanaki, A. Gunasekaran, and R. Dubey, “Towards the next generation of manufacturing: implications of big data and digitalization in the context of industry 4.0," Production planning and control, pp. 1-4, 2021, doi: 10.1080/09537287.2020.1810767.

[2] A. Kaplan and M. Haenlein, "Siri, Siri, in my hand: Who's the fairest in the land? On the interpretations, illustrations, and implications of artificial intelligence," Business Horizons, vol. 62, no. 1, pp. 15-25, 2019, doi: 10.1016/j.bushor.2018.08.004.

[3] H. Bhardwaj, P. Tomar, A. Sakalle, and U. Sharma, "Principles and Foundations of Artificial Intelligence and Internet of Things Technology," in Artificial Intelligence to Solve Pervasive Internet of Things Issues: Elsevier, 2021, pp. 377-392.
[4] R. T. Kreutzer, M. Sirrenberg, and others, Künstliche Intelligenz verstehen: Springer, 2019.

[5] A. Schühly, F. Becker, and F. Klein, Real Time Strategy: When Strategic Foresight Meets Artificial Intelligence: Emerald Group Publishing, 2020.

[6] J. Iden, L. B. Methlie, and G. E. Christensen, "The nature of strategic foresight research: A systematic literature review," Technological Forecasting and Social Change, vol. 116, no. 9, pp. 87-97, 2017, doi: 10.1016/j.techfore.2016.11.002.

[7] M. B. Cavalheiro, G. M. d. C. Cavalheiro, V. F. Mayer, and O. R. B. Marques, "Applying patent analytics to understand technological trends of smart tourism destinations," Technology Analysis \& Strategic Management, vol. 12, no. 6, pp. 1-17, 2021, doi: 10.1080/09537325.2020.1870950.

[8] I. Gräßler, P. Scholle, and H. Thiele, "IMPROVING SCENARIO-TECHNIQUE BY A SEMI-AUTOMATIZED CONSISTENCY ASSESSMENT BASED ON PATTERN RECOGNITION BY ARTIFICIAL NEURAL NETWORKS," Proc. Des. Soc.: Des. Conf., vol. 1, pp. 147-156, 2020, doi: 10.1017/dsd.2020.279.

[9] L. d. S. Nascimento, F. M. Reichert, R. Janissek-Muniz, and P. A. Zawislak, "Dynamic interactions among knowledge management, strategic foresight and emerging technologies," JKM, ahead-of-print, ahead-of-print, p. 1, 2020, doi: 10.1108/JKM-01-2020-0044.

[10] D. Ehls, S. Polier, and C. Herstatt, "Reviewing the Field of External Knowledge Search for Innovation: Theoretical Underpinnings and Future (Re-)search Directions," J Prod Innov Manag, vol. 37, no. 5, pp. 405-430, 2020, doi: 10.1111/jpim.12549.

[11] F. O. Oluwatosin, "An Exploration on the Significance of Data Science in Organisational Development," Journal of Public Administration and Social Welfare Research, vol. 5, no. 2, 2020.

[12] L. van Audenhove and K. Donders, "Talking to People III: Expert Interviews and Elite Interviews," in The Palgrave Handbook of Methods for Media Policy Research, H. van den Bulck, M. Puppis, K. Donders, and L. van Audenhove, Eds., Cham: Springer International Publishing, 2019, pp. 179-197. [Online]. Available: https://www.tandfonline.com/doi/full/10.1080/13645579.2020.1766777

[13] S. Döringer, "'The problem-centred expert interview'. Combining qualitative interviewing approaches for investigating implicit expert knowledge," International Journal of Social Research Methodology, vol. 1, no. 4, pp. 1-14, 2020, doi: 10.1080/13645579.2020.1766777.

[14] B. Flyvbjerg, "Five Misunderstandings About Case-Study Research," Qualitative Inquiry, vol. 12 , no. 2, pp. 219-245, 2006, doi: 10.1177/1077800405284363.

[15] A. Kurz, C. Stockhammer, S. Fuchs, and D. Meinhard, "Das problemzentrierte Interview," in Qualitative Marktforschung: Konzepte - Methoden - Analysen, R. Buber and H. H. Holzmüller, Eds., Wiesbaden: Gabler, 2007, pp. 463-475.

[16] H. O. Mayer, Interview und schriftliche Befragung, 4th ed. München: Oldenbourg, 2009.

[17] A. Witzel, "The problem-centered interview. FQS Forum: Qualitative Sozialforschung," in Forum: Qualitative Social Research [On-line Journal], 2000, p. 22.

[18] S. Albers, D. Klapper, U. Konradt, A. Walter, and J. Wolf, "Methodik der empirischen Forschung. 3., überarbeitete und erweiterte Auflage," Wiesbaden and sl: Gabler Verlag, 2009. 